\title{
Living with digestive stomas: strategies to cope with the new bodily reality ${ }^{1}$
}

\author{
Candela Bonill-de-las-Nieves² \\ Miriam Celdrán-Mañas ${ }^{3}$ \\ César Hueso-Montoro ${ }^{4}$ \\ José Miguel Morales-Asencio ${ }^{2}$ \\ Concha Rivas-Marín ${ }^{5}$ \\ Magdalena Cuevas Fernández-Gallego ${ }^{6}$
}

Objective: the objective in this study was to describe the strategies developed by digestive stoma patients to cope with their situation. Method: a qualitative and descriptive study was undertaken, involving 21 stoma patients living in the provinces of Málaga and Granada (Spain). The informants were selected in accordance with criteria of appropriateness and diversity, through intentional sampling. The data were collected by means of semistructured interviews. Results: the content analysis revealed three categories around which the distinct strategies were developed: Selfcare, Adaptation to the bodily change and Self-help. Conclusion: the strategies developed are focusing on achieving the effective management of the stoma and are closely linked with the achievement of autonomy. Discovering the strategies applied is fundamental for the nursing professionals to offer high-quality care, centered on people and their process.

Descriptors: Adaptation, Psychological; Self Care; Colostomy; Ileostomy; Qualitative Research.

\footnotetext{
${ }_{1}^{1}$ Paper extracted from doctoral dissertation "Stories and experiences of people living with digestive stomas", presented to Facultad de Ciencias de la Salud, Universidad de Málaga, Spain. Supported by Consejería de Salud de la Junta de Andalucía, project \# PI-0099-2010.

${ }^{2} \mathrm{PhD}$, Professor, Facultad de Ciencias de la Salud, Universidad de Málaga, Málaga, Spain.

${ }^{3}$ MSc, RN, Servicio Andaluz de Salud, Andalucía, Spain.

${ }^{4}$ PhD, Professor, Facultad de Ciencias de la Salud, Universidad de Granada, Granada, Spain.

${ }^{5} \mathrm{RN}$, Hospital Universitario Virgen de la Victoria, Málaga, Spain.

${ }^{6}$ MSc, RN, Centro de Salud Portada Alta Málaga, Málaga, Spain. RN, Centro de Salud Colonia Santa Inés-Teatinos, Málaga, Spain.
}

Corresponding Author:

Candela Bonill-de-las-Nieves

Universidad de Málaga. Facultad de Ciencias de la Salud

C/ Arquitecto Francisco Peñalosa, 3

29071, Málaga, España

E-mail: candela_bonill@yahoo.es
Copyright (c) 2014 Revista Latino-Americana de Enfermagem This is an Open Access article distributed under the terms of the Creative Commons Attribution Non-Commercial License (CC BY-NC).

This license lets others distribute, remix, tweak, and build upon your work non-commercially, and although their new works must also acknowledge you and be non-commercial, they don't have to license their derivative works on the same terms. 


\section{Introduction}

Digestive stomas (ileostomy and colostomy) are installed for therapeutic purposes in different illnesses, such as Colorectal Cancer, Intestinal Inflammatory Diseases, including Crohn's Disease and Ulcerous Colitis, hereditary diseases like Family Polyposis, abdominal traumas and congenital diseases, with Colorectal Cancer as the main motive to install a stoma(1-2). People who turn into ostomists after a surgery have to cope with a series of difficulties, related to the loss of anal sphincter control and the presence of an intestinal part in the abdomen through which feces and gases are eliminated. After the surgery, the patients are expected to effectively assume physiological functions their body used to perform autonomously until then. The loss of continence associated with the creation of the stoma is experienced as a more severe personality change than in case of other mutilations, even if those are less easy to dissimulate than the stoma. It can change the patients' social life and make them think that they are not completely normal and feel different because they do not display the characteristics and attributes society considers as normal, due to their imperfect body ${ }^{(3-5)}$.

The set of coping forms these people adopt to face their new situation seems to include a range of answers, centered on the problem as well as on emotions, such as the mood, the acknowledgement of positive changes, repression, denial, normalization, resignification or cover-up ${ }^{(4,6-9)}$. Self-efficacy, considered as the ability to perform specific tasks related to stoma care, seems to favor a better psychosocial adaptation and quality of life ${ }^{(10)}$.

The objective in this study was to describe the strategies developed by digestive stoma patients to cope with their situation. The few studies that have focused on the coping strategies of stoma patients have departed from stress theory and Lazarus and Strauss' coping strategies as frameworks to understand the subjects' conducts, although with different methodological approaches ${ }^{(6-8,10)}$. Qualitative studies are needed that address the research problem from other perspectives. The premises of descriptive phenomenology, centered on understanding the experiences of the people who are part of the phenomenon as they describe them can help us to understand the singular experience lived during this process and their different forms of adaptation to or coping with their new bodily reality ${ }^{(11)}$.

\section{Methods}

A descriptive and qualitative study was undertaken, based on Edmund Husserl's descriptive phenomenology(12), which included digestive stoma patients (colostomy and ileostomy) as a consequence of different illnesses (Cancer, Crohn's Disease, Ulcerous Colitis, Family Polyposis) living in the provinces of Málaga and Granada (Spain). The informants were obtained through stomatherapy nurses. For their selection, the criteria of appropriateness of the informants and diversity of viewpoints were adopted, using the disease that caused the stoma, the stoma type, the dwell time of the stoma, gender and age as diversification criteria. For the sampling procedure, intentional sampling guidelines were followed, reaching the information saturation points after 21 informants' discourse.

The data were collected through semistructured interviews. The interviews were held between January and June 2011 and took 35-40 minutes. A previously elaborated script was used, containing questions taken from the main themes addressed in similar studies undertaken in other contexts. The interviews started with open questions, such as "tell me about the care your stoma demands", which contributed for the informants to talk about what they found important without structuring their answers, leaving the central questions to be asked further on: In what aspects of your stoma care do you think you've improved?, What aspects or situations have seemed more difficult to you? Why do you think it has been like that? ¿How have you solved them? What things help you to have more strength to cope with this situation? etc. The interviews were transcribed and the notes from the field diary were incorporated.

A descriptive analysis was undertaken, based on Taylor-Bogdan's proposal, adopting a sequential order based on the following steps: data preparation, data organization in categories and codes and interpretation of the data. This proposal implies that the analysis phases happen subsequently, or what some authors have called a successive approach or ongoing analysis ${ }^{(13)}$. For the analysis, the software Atlas-ti was used.

The informants were asked to give their verbal and written consent, as well as their permission to record the interviews. Anonymity was preserved, using fictitious names, and the confidentiality of the information was guaranteed based on current legislation (LAW 15/1999, from December $\left.13^{\text {th }}\right)$. Authorization for the study was obtained from the Research Committee at the School of Health Sciences of the Universidad de Málaga. 


\section{Results}

In the end, 21 patients were interviewed, whose main characteristics have been detailed in Table 1.

The strategies the patients highlighted to be able to cope with their situation were focused on technical issues regarding self-care (irrigation, eating, skin and stoma hygiene and care, pouch change and use of other kind of devices) and technical aspects to solve problems related to gases and the escape of feces; they also underlined actions focused on the adaptation to the bodily change and a final set of activities aimed at self-help.

Table 1 - Sociodemographic and clinical characteristics of the study population, Málaga and Granada, Spain

\begin{tabular}{|c|c|c|c|c|c|c|c|}
\hline \multirow{2}{*}{ Name (Code) } & \multirow{2}{*}{ Sex } & \multirow{2}{*}{ Age } & \multirow{2}{*}{ Diagnosis } & \multicolumn{3}{|c|}{ Stoma } & \multirow{2}{*}{$\begin{array}{c}\text { Professional } \\
\text { status }\end{array}$} \\
\hline & & & & Type & Stoma dwell time & Time & \\
\hline Antonio (C1) & Man & 63 & Colon Cancer & Ileostomy & Temporary & 4 months & Retired \\
\hline Luis (A1) & Man & 68 & Colon Cancer & Colostomy & Definitive & 9 years & Retired \\
\hline Miguel (C2) & Man & 73 & Colorectal Cancer & Colostomy & Definitive & 5 years & Retired \\
\hline María (C3) & Woman & 45 & Anal Cancer & Colostomy & Definitive & 7 years & Active \\
\hline Fernando (A2) & Man & 61 & Rectal Cancer & Colostomy & Temporary & 18 months & Retired \\
\hline Ana (A3) & Woman & 50 & Rectal Cancer & Colostomy & Definitive & 4 months & On leave \\
\hline Laura (A4) & Woman & 47 & Sigmoid Cancer & Colostomy & Temporary & 1 month & On leave \\
\hline Marta (A5) & Woman & 40 & Crohn's Disease & lleostomy & Definitive & 2 years & Retired \\
\hline Daniel (A6) & Man & 75 & Colon Cancer & Colostomy & Definitive & 11 years & Retired \\
\hline Jesús (C4) & Man & 44 & Ulcerous Colitis & Ileostomy & Definitive & 7 years & Retired \\
\hline Pablo (C5) & Man & 47 & Crohn's Disease & Ileostomy & Definitive & 7 years & On leave \\
\hline Pedro (A7) & Man & 52 & Crohn's Disease & Colostomy & Definitive & 4 years & Retired \\
\hline Antonia (A8) & Woman & 54 & Family polyposis & Ileostomy & Definitive & 10 years & Active \\
\hline Felipe (L1) & Man & 59 & Colon Cancer & Colostomy & Temporary & 16 months & Retired \\
\hline David (L2) & Man & 57 & Rectal Cancer & Ileostomy & Temporary & 4 months & On leave \\
\hline Rosa (L3) & Woman & 68 & Colon Cancer & Ileostomy & Temporary & 2 months & Retired \\
\hline Manuel (C6) & Man & 64 & Colon Cancer & Ileostomy & Temporary & 3 months & Retired \\
\hline Luisa (C7) & Woman & 23 & Ulcerous Colitis & lleostomy & Temporary & 1 month & On leave \\
\hline Isabel (C8) & Woman & 55 & Crohn's Disease & Ileostomy & Definitive & 21 years & Retired \\
\hline Marina (A9) & Woman & 35 & Colon Cancer & Colostomy & Definitive & 4 years & Active \\
\hline Paco (C9) & Man & 60 & Colon Cancer & Colostomy & Definitive & 14 months & Retired \\
\hline
\end{tabular}

\section{Self-care}

Irrigation

Doing irrigation is a matter closely linked with autonomy, as it allows people to control their bowel and bladder movements, in a way achieving continence, as they can spend around 48 hours without stools.

The irrigations allow you to control the bowel and bladder movements. So you say: Tomorrow I've got an important event, so the day before I do the irrigation, so the next day I won't have problems, neither with gases nor with anything. (A9)

The contact with the irrigation demands a process of assimilation and learning that starts with a phase of conflict, followed by normalization.

At first, while you are improving your technique you've got accidents, but then you get accustomed and see it as something natural and normal. Today it's like shaving, I've included it as a part of hygiene. (A2)
On the other hand, the lack of knowledge about this technique can make the people be reluctant to practice it, despite the benefits it offers.

No, I don't do that, nor will I. It seems anti-hygienic [strongly affirms this] [...] They have not explained anything to me. (L1)

For the people who are unable to do irrigation, for different reasons, this lack of control is seen as a drawback.

I cannot do the irrigations because it's an ileostomy, I could if it were a colostomy [...] When I was in hospital, I heard the people say: $A$. [stomatherapist nurse] why do you do the irrigations? Can I do that too? And she explained to me: No, you've got an ileo [...] In the colostomy it's the large intestine, that's a joy, but with the ileo it's always coming out. (A8)

Eating

Eating control is another relevant action to avoid collateral complications, such as smells, 
gases, as well as to control the bowel and bladder movements.

You have to know three or four things that help you with the smell. A. [stomatherapist] told me to have yoghurt, but I've also read that citrus fruit and other foods are good. (A3)

Hygiene, skin-stoma care, pouch change

The patients perform the hygiene, skin and stoma care and pouch changes completely normal, using those times of day with less intestinal transit, like early in the morning.

I remove the pouch and have a shower. You have to find the right time, early in the morning for example, I don't have breakfast and have a shower calmly, without any problem whatsoever. (C1)

As regards the pouch change itself, although this does not suppose any problem for most informants and can be done anywhere, the ileostomy patients refer to the importance of appropriate toilet facilities, considering both the cleanliness and absence of uncomfortable conditions to perform the change. Among the hygiene strategies, the use of large toilet facilities is highlighted and, in terms of comfort, they use adapted facilities, devised for other groups (disabled).

Nevertheless, the situation is different for people with a sunken stoma, which demands greater care, on the one hand to avoid the development of skin problems, and on the other to avoid the production of fungus, due to the difficulties of dealing with a device that appropriately adapts to their stoma.

The stoma was sunken, so I had a lot of leaks, my skin was always bad, it was a lot of care. (C8)

\section{Different devices}

About the use of devices, the importance of having a large variety to choose from is highlighted, in function of each situation, facilitating the patients' daily life. The pouches reveal the current technological quality, considering both the inhibition of smells and the easy management and comfort.

The pouches used to be very primitive. Today, increasingly personalized products are being launched, they contain carbon to inhibit the smell, well, many things that grant you quality of life, that make your life easier. (A1)

Colostomy patients who do irrigation can also use other devices, such as shutters and stoma covering devices (mini-pouches). The advantage of the shutters is that they inhibit the noise and offer the comfort of not carrying a hanging pouch. In some cases, however, these advantages turn into drawbacks, as they can cause problems due to the pressure exerted in the stoma, as well as leakage problems because of the absence of a minimal deposit in case of some bowel or bladder movement. Therefore, most patients use the stoma covering devices (mini-pouches).

I use the stoma cover, instead of the shutter, when I know that the stool is going to come out, because the shutter puts pressure and bothers you, and the cover allows you to reach the bathroom while the stool comes out or not. (A9)

\section{Gas management and stool leakages}

Another issue that needs to be highlighted is the production of gases and the presence of leakages, because of their repercussions for stoma patients. At first, the production of gases causes shame, bother or fear in some cases, considering it as something they cannot control. Nevertheless, they refer to the importance of assuming this, considering it as unimportance and seeing it jokingly.

I was afraid: To make sure that it doesn't make noise [...] But, little by little, you say: Well, that's it. Let the gases be heard, because nothing happens. (C8)

Differences are observed in the positions taken towards these situations, among the people who have used a stoma for longer or shorter periods.

Adaptation to the bodily change

With regard to the bodily change, different strategies have been identified. Due to the location of the stoma, people with ileostomies feel more comfortable when using straps instead of a belt. As regards changing underwear, this serves to avoid leakages in ileostomy patients while, in colostomy patients, this change helps to fix the pouch better and, consequently, achieve more comfort. Concerning the use of swimming clothes, the strategies range from accepting the use of a bathing suit instead of a bikini to developing strategies to keep on using a bikini, like the use of shutters together with adhesive tattoos. Nevertheless, some strategies appear which are aimed at hiding. These actions are related to changes in the way of dressing, installing the pouch or going to the beach, with a view to avoiding that other people perceive its existence.

As I was really looking forward to wearing a bikini again, I found some tattoos, the adhesive type. So, I put on the shutter on top I put a kind of skin-colored strips that just differ from the skin, and on top I put the tattoo. And that's how I wear my bikini. (A9)

My kids think I wear a large swimsuit because I like to. People with stomas do not go to the beach often and we try not 
to use tight-fitting clothes so that the pouch doesn't create a bump. (C5)

It has been identified that the technical actions and actions aimed at the adaptation to the bodily change are strengthened in the different possible situations. This line is based on the roaming between the information the stomatherapy nurse offers and the knowledge and skills the subjects gain through their own experience.

\section{Self-help}

Search for Internet information and peer support

An increasing number of people or family members find the information they need to solve their doubts through the Internet. This information does not always entail positive effects though (support for decision making) and can favor the development of feelings of fear and despair, create doubts about their trustworthiness, or confuse, coming from contexts with resources that do not exist in the patients' own context.

My daughter had searched the Internet, and yes it helped us. What happens is that some guides tell you: Your specialized nurse will provide you with the indications before leaving the hospital, but the nurse was not there. That was really hard, because we did not have anything else. (C1)

When I had found out what a colostomy was, what the information implied, I found out all of that through the Internet, because the initial reactions were marked by despair, thinking whether it was worth it, or how far it had brought us. (C9)

The importance of the availability of the peer group should be highlighted, due to the credibility they attribute to the information coming from people who have gone through the same, considering them as references. This has been observed at the level of individual patients as well as associations, which people turn to in order to express their feelings, concerns, doubts, as well as to share their experiences, producing a very positive feedback, at the emotional as well as the technical level, which helps them cope with the different situations living with a digestive stoma entails.

Fortunately there is an association of stoma patients. Being able to talk to people who have the same thing as you is extremely, is very important. Mainly in the beginning, when you feel so insecure [...] So, talking to people who've had this for many years calms you down and gives you many things. (A9)

This is so important and offers so many benefits that some of the informants demonstrate their availability to tell their experience, inflaming a feeling of solidary in these people for helping others who are going through similar situations.
I am available for anything that is missing, because I understand that the professionals have a completely fundamental, basic role, but this part of the experience-based reference, we only get that from people like ourselves. (C8)

There have also been less positive experiences with peer groups, when the person who was giving support to cope with the new bodily reality did not seem to have accepted being a stoma patient.

I found out through another friend of the Ulcerous Colitis Association, and a person came to see me friendly, a stoma patient, to give me some explanation. But it wasn't very useful because the man was kind of depressed, he did not give a pretty description. (C5)

\section{Discussion}

The study informants' profile represents the characteristics that define the prevalence and incidence of digestive stomas. It should be highlighted that men and women are distributed homogeneously, all adults with a mean age of about 50 years. In most patients, the disease that originated the ileostomy or colostomy is cancer-related. The heterogeneous characteristics should be appointed with regard to the definitive or temporary nature of the stoma, how long the informants have used it and their professional status, so as to cover the range of viewpoints on the research problem. Thus, the considerations that should be emphasized in the discussion take into account a diverse selection of subjects that represents the study phenomenon.

The strategies developed to cope with the situation are focused on achieving the effective management of the stoma, consequently improving the quality of life and adaptive processes ${ }^{(6,14)}$, in short, favoring the normalization of these people's lives.

The benefits of irrigation grant the subjects the possibility of living a fuller life and with less limitations, endorsed by the autonomy this technique endorses in digestive stoma patients(15-17). Nevertheless, it has been observed that lack of knowledge about this technique can make the people feel reluctant to practice it, despite the benefits it offers. This explains the importance of correct information and teaching ${ }^{(14,16)}$. As regards skin and stoma hygiene and care, it has been observed that people with a sunken stoma demand greater care to avoid leakages and skin problems. Therefore, having a sunken stoma can act as a conditioning factor in coping with the situation ${ }^{(18-19)}$.

As regards the use of devices, the importance of having a wide range of devices available to choose from in function of each situation is highlighted, 
facilitating the patients daily life and improving their quality of life $\mathrm{e}^{(18,20)}$.

In the management of gases and leakages, a link has been observed between the time factor and the ability to cope with these situations. Nevertheless, the feelings the presence of leakages provokes remain the same $^{(21)}$. As a result of the leakages, the patients can change from discreditable to discredited, due to the quality of being different, represented by the stoma, which is revealed to the others when a leakage happens or the patient experiences gases, which can lead to the absence of social acceptance(3).

The search for information on the Internet figures as a strategy the digestive stoma patients increasingly use. This is a novel fact in the approach to this kind of problem, as it implies the need for professionals to actively participate in the elaboration of information the patients have at their disposal when searching the Internet, creating a very interesting professional activity area. Studies about Internet use as a source of information have revealed that the use of the Internet to find specialized information increases with the amount of needs that are not attended to; in the case of unattended emotional support needs, the trend rests on the use of social networks on the web ${ }^{(22)}$. Other authors have confirmed that the patients' low satisfaction level with the care received is a factor associated with greater Internet use to seek information(23).

On the other hand, being able to count on the peer group is very important due to the credibility the patients grant to the information. At the level of individuals as well as associations, the peer group helps them to cope with the different situations living with the stoma entails ${ }^{(6,24)}$. On some occasions, this help seems to condition a feeling of reciprocity, showing their willingness to help others who are going through similar situations ${ }^{(25)}$.

\section{Conclusions}

These study results show how the strategies developed to cope with the situations are focused on the normalization of the process, with a view to achieving the effective management of the stoma, so that it interferes as little as possible in their daily lives, favoring an adaptation process. In those people who are able to apply these strategies, greater feelings of control and confidence are observed, reducing the fears of social rejection. The development of these strategies is closely linked with the achievement of autonomy.

\section{Limitations}

In most of the informants who participated in the study, the cause of the stoma was a cancer-related process. Although this representation is related to the prevalence and current incidence of the problem, we find it necessary to investigate the discourse of digestive stoma patients for other than cancer-related causes in further detail.

The informants' discourse reveals the importance they grant to autonomy, but it is not clear when they become aware of its importance. Therefore, questions persist as to what periods and circumstances favor the development of autonomy in self-care for the disease.

\section{Recommendations}

The evidences based on qualitative studies can help to improve the effectiveness of the nursing interventions. This research offers up-to-date evidence about the coping strategies used by digestive stoma patients. In that sense, nurses can use these findings to include those positive strategies that can help to cope with the situation into their preventive interventions, such as: Informing and teaching about the irrigation technique, about the different devices available in the market for stoma patients and about stoma care and hygiene, paying special attention to the escape of gases and stool leakages, as well as to people with sunken stomas. The importance of peer groups should also be acknowledged with a view to achieving effective stoma management in an early manner, facilitating the contact with associations of individual stoma patients who can share their experience. In accordance with the study findings, these interventions will directly influence the patients' effective coping with the problem, furthering their emotional responses.

\section{References}

1. Violin MR, Mathias TAF, Uchimura TT. Perfil de clientes colostomizados inscritos em programa de atençãoaosestomizados". Rev Eletr Enferm. [Internet]. 2008. [acesso 3 março 2013];10(4). Disponível em: http://www.fen.ufg.br/revista/v10/n4/v10n4a05.htm

2. Santos CHM, Becerra MM, Becerra FMM, Paraguassú BR. Perfil do Paciente Ostomizado e Complicações Relacionadas ao Estoma. Rev Bras Coloproct. 2007;27(1):16-9.

3. Goffman E. Estigma. La identidad deteriorada. Buenos Aires: Amorrortu; 2008. 
4. Silva AL da, Shimizu HE. The meaning of the new way of life of individuals with permanent intestinal ostomy. Rev. Latino-Am. Enfermagem. 2006;14(4):483-90.

5. Pulido R, Sánchez J, Baraza A. Cultura, educación y cuidados en la atención al paciente ostomizado. Cultura de los Cuidados. 2001;5(10):100-8.

6. Martín B, Panduro RM, Crespillo Y, Rojas L, González S. El proceso de afrontamiento en personas recientemente ostomizadas. Index Enferm. 2010;19(2-3):115-9.

7. Krouse RS, Grant M, Rawl SM, Mohler MJ, Baldwin $\mathrm{CM}$, Coons SJ, et al. Coping and acceptance : The greatest challenge for veterans with intestinal stomas. J Psychosom Res. 2009;66(3):227-33.

8. Barnabe NC, Dell Acqua MCQ. Coping strategies of ostomized individuals. Rev. Latino-Am. Enfermagem. 2008;16(4):712-9.

9. Petuco VM, Martins CL. Quase como antes. A ressignificação da identidade da pessoa estomizada com cáncer. O mundo da Saúde. 2006;30(1):52-4.

10. Wu HK, Chau JP, Twinn S. Self-efficacy and Quality of Life Among Stoma Patients in Hong Kong. Cancer Nurs. 2007;30(3):186-93.

11. Hueso C, Siles J, Amezcua M, Bonill C, Pastor S, Celdrán M. Understanding the suffering of a patient with an illness: signs, context and strategies. Rev. LatinoAm. Enfermagem 2012 20(3):619-28.

12. Husserl E. The crisis of European Sciences and transcendental phenomenology. Evanston, IL: Northwestern University Press; 1970.

13. Amezcua M, Hueso C. Cómo analizar un relato biográfico. Arch Memoria. [Internet]. 2009; [acesso 15 março 2013]. 6(3). Disponível em: http://www.index-f. com/memoria/6/mc30863.php

14. Simmons KL, Smith JA, Bobb K, Liles LLM. Adjustment to colostomy: stoma acceptance, stoma care self-efficacy and interpersonal relationships. J Adv Nurs. 2007;60(6):627-35.

15. Maruyama SAT, Barbosa CS, Bellato R, Pereira WR, Navarro JP. Auto-irrigação - estratégia facilitadora para a reinserção social de pessoas com colostomía. Rev Eletr Enferm. [Internet]. 2009; [acesso 15 março 2013]; 11(3):665-73. Disponível em: www.fen.ufg.br/revista/ v11/n3/pdf/v11n3a26.pdf

16. Varma $\mathrm{S}$. Issues in irrigation for people with a permanent colostomy:a review. $\mathrm{Br} J$ Nurs. 2009;18(4):S15-8.

17. Carlsson E, Gylin M, Nilsson L, Svensson K, Alverslid I, Persson E. Positive and negative aspects of colostomy irrigation: a patient and WOC nurse perspective. J Wound Ostomy Continence Nurs. 2010;37(5):511-6.
18. Black P. Choosing the correct stoma appliance. $\mathrm{Br}$ J Nurs. 2009;18(4):S10, S12-4.

19. Butler DL. Early Postoperative Complications Following Ostomy Surgery. J Wound Ostomy Continence Nurs. 2009;36(5):513-9.

20. Rudoni C, Dennis H. Accessories or necessities? Exploring consensus on usage of stoma accessories. $\mathrm{Br}$ J Nurs. 2009;18(18):1106-12.

21. Redmond C, Cowin C, Parker T. The experience of faecal leakage among ileostomists. $\mathrm{Br}$ J Nurs. 2009;18(17):S12-7.

22. Lee SY, Hawkins R. Why do patients seek an alternative channel? The effects of unmet needs on patients' health-related Internet use. J Health Commun. 2010;15(2):152-66.

23. Tustin N. The role of patient satisfaction in online health information seeking. J Health Commun. 2010;15(1):3-17.

24. Pereira APS, Pelá NTR. Atividades grupais de portadores de estoma intestinal definitivo: a busca da aceitação. Rev Enferm UERJ. 2006;14(4):574-9.

25. Violin MR, Sales CA. Experiências cotidianas de pessoas colostomizadas por câncer: enfoque existencial. Rev Eletr Enferm. [Internet]. 2010; [acesso 13 jan 2013]; 12(2):278-86. Disponível em: http://www.fen. ufg.br/revista/v12/n2/pdf/v12n2a08.pdf 